\title{
Stanniocalcin-1 promotes cell proliferation, chemoresistance and metastasis in hypoxic gastric cancer cells via Bcl-2
}

\author{
YAN WANG ${ }^{1,2^{*}}$, ZIHAO Q $^{3 *}$, MENGLONG ZHOU $^{1,2}$, WANG YANG $^{1,2}$, RAN HU $^{1,2}$, \\ GUICHAO LI $^{1,2}$, XUEJUN MA ${ }^{1,2}$ and ZHEN ZHANG ${ }^{1,2}$ \\ ${ }^{1}$ Department of Radiation Oncology, Fudan University Shanghai Cancer Center; \\ ${ }^{2}$ Department of Oncology, Shanghai Medical College, Fudan University, Shanghai 200032; \\ ${ }^{3}$ Department of Surgery, Huadong Hospital affiliated to Fudan University, Shanghai 200040, P.R. China
}

Received August 8, 2018; Accepted January 4, 2019

DOI: $10.3892 /$ or.2019.6980

\begin{abstract}
Gastric cancer (GC) is one of the most lethal diseases worldwide, but the mechanism of GC development remains elusive. In the present study, the roles of stanniocalcin-1 (STC1) in GC were investigated. It was demonstrated that overexpression of STC1 mRNA and protein were associated with poor survival of patients with GC. The expression of STC1 was enhanced in hypoxic GC cells and overexpression of STC1 facilitated cell proliferation in hypoxia but not in normoxia. Furthermore, STC1 promoted chemoresistance, migration and invasion in hypoxia. Upregulating the expression of STC1 enhanced the expression of B cell lymphoma (Bcl)-2, neural-cadherin and matrix metalloproteinase-2, whereas it reduced the levels of cytochrome $c$, cleaved-caspase-9, cleaved-caspase-3 and epithelial-cadherin. However, downregulation of STC1 altered the expression of these proteins in the opposite direction. Furthermore, disturbing the expression of Bcl-2 partly reversed the changes to these proteins and also the pro-proliferation, anti-apoptosis and pro-invasion potential of STC1. In vivo experiments indicated that enhanced expression of STC1 promoted tumor growth and metastasis in mice. Collectively, the results indicated that STC1 may serve an oncogenic role in hypoxic GC via dysregulating Bcl-2, indicating that STC1 may be a potential therapeutic target in the treatment of GC.
\end{abstract}

Correspondence to: Dr Zhen Zhang or Dr Xuejun Ma, Department of Radiation Oncology, Fudan University Shanghai Cancer Center, 270 Dong'an Road, Shanghai 200032, P.R. China

E-mail: zhen_zhang@fudan.edu.cn

E-mail: chateauma@hotmail.com

${ }^{*}$ Contributed equally

Abbreviations: GC, gastric cancer; STC1, stanniocalcin-1; OS, overall survival; FP, first progression

Key words: stanniocalcin-1, B cell lymphoma-2, hypoxia, apoptosis, metastasis, gastric cancer

\section{Introduction}

Gastric cancer (GC) is one of the most lethal diseases in the world (1). Hypoxia is a general problem in solid tumors, including GC. Hypoxic cells undergo pro-survival alterations, including improved proliferation and invasion ability and enhanced resistance to chemotherapy $(2,3)$. Therefore, actions to clarify the mechanisms and restrain the malignant behavior of hypoxic GC are not only vital but also urgent.

Stanniocalcin-1 (STC1), a glycoprotein involved in calcium/phosphate homeostasis, was demonstrated to be elevated in several types of carcinoma tissue compared with in corresponding normal tissue (4-7). Notably, Fang et al (7) reported that overexpression of STC1 in tissue from GC was associated with a poor prognosis, but the mechanisms are unclear. Notably, the expression of STC1 could be induced by hypoxia $(8,9)$. Therefore, for better control of GC, it is necessary to elucidate the roles of STC1 in hypoxic GC and identify proper therapeutic targets.

B cell lymphoma-2 (Bcl-2), one of the key proteins upstream of the apoptotic cascade (10), also serves roles in hypoxia (11). Given that overexpression of STC1 elevated the levels of Bcl-2 under normal conditions (4), it is possible that STC1 works together with Bcl-2 in a hypoxic environment.

In the present study, the roles of STC1 in GC were investigated. It was demonstrated that under hypoxic conditions, STC1 probably promoted cell proliferation, chemoresistance and metastasis in $\mathrm{GC}$ via positively regulating $\mathrm{Bcl}-2$, suggesting that STC1 and Bcl-2 may be potential targets in the treatment of GC.

\section{Materials and methods}

Cell lines and cell culture. GC cell lines HGC27 (\#TCHu22) and NCIN87 (\#SCSP-534) were obtained from the Cell Bank of Type Culture Collection of the Chinese Academy of Sciences (Shanghai, China); MKN28 (\#3111C0001CCC000482) and MKN45 (\#3111C0001CCC000229) cells were obtained from The National Infrastructure of Cell line Resource (Beijing, China); SNU601 cells were obtained from the Korean Cell Line Bank (Seoul, Korea); SNU216 cells were provided by the Medical College of Xiamen University (Xiamen, China). 
Retroviral packaging cells (Phoenix amphotropic cells) were gifts from Professor Gong Yang at Fudan University Shanghai Cancer Center (Shanghai, China). Cells were cultured in Minimum Essential Medium (cat. no. 11095-080; HGC27) or RPMI1640 medium (cat. no. 12633-012) containing 10\% fetal bovine serum (cat. no. 10099-141; all from Gibco; Thermo Fisher Scientific, Inc., Waltham, MA, USA), 100 units/ml penicillin and $100 \mu \mathrm{g} / \mathrm{ml}$ streptomycin. To simulate ahypoxic environment in vitro, cells were incubated with $100 \mu \mathrm{M}$ cobalt chloride $\left(\mathrm{CoCl}_{2}\right.$; Sigma Aldrich; Merck KGaA, Darmstadt, Germany) for at least $48 \mathrm{~h}$ according to different procedures. All cells were cultured or treated in a humid atmosphere at $37^{\circ} \mathrm{C}$ with $5 \% \mathrm{CO}_{2}$ and $95 \%$ air.

It has been reported that MKN28, a kind of gastric tubular adenocarcinoma, was contaminated with MKN74, another gastric tubular adenocarcinoma cell line (12). However, throughout the study MKN28 was used, and the results are repeatable.

Cell transfection and viral infection. The retroviral plasmids carrying STC1 cDNA and the empty vector ( $\mathrm{Vec}$ ), small hairpin RNA (shRNA) against the open reading frame of STC1 mRNA and the scrambled shRNA (Scr) were provided by Professor Gong Yang. The cells were infected as described previously (4).

SNU601-STC1 cells were transfected with either $50 \mathrm{nM}$ Bcl-2-targeting small interfering (si)RNA (Bcl2i; targeting sequence, CAGGACCTCGCCGCTGCAGAC) (13) or scrambled negative controls ( $\mathrm{NCi}$; target sequence, AAT TCTCCGAACGTGTCACGT; Shanghai GenePharma Co., Ltd., Shanghai, China) (13) using the Lipofectamine 2000 transfection reagent (Invitrogen; Thermo Fisher Scientific, Inc.) according to the manufacturer's protocol. Cells were then incubated for $48 \mathrm{~h}$ prior to subsequent experiments.

Immunoblotting analysis. To analyze protein levels in hypoxic or normoxic cells, cells were treated with or without $\mathrm{CoCl}_{2}$ for $48 \mathrm{~h}$, and immunoblotting analysis was performed as previously described (14). The following antibodies were used for immunoblotting: STC1 (cat. no. 20621-1-AP; 1:1,000), hypoxia inducible factor (HIF)-1 $\alpha$ (cat. no. 66730-1-Ig; 1:5,000), epithelial (E)-cadherin (cat. no. 20874-1-AP; 1:1,000; all ProteinTech Group, Inc., Chicago, IL, USA), Bcl-2 (cat. no. sc-7382; $1: 500$ ), caspase-9 (cat. no. sc-56076; 1:500), caspase-3 (cat. no. sc-7148; 1:500), neural (N)-cadherin (cat. no. sc-1502; 1:1,000; all Santa Cruz Biotechnology, Inc., Dallas, TX, USA), matrix metalloproteinase (MMP)-1 (cat. no. M4427; 1:1,000; Sigma-Aldrich; Merck KGaA), X-linked inhibitor of apoptosis protein (XIAP; cat. no. cs-2045; $1: 1,000$ ) and $\beta$-actin (cat. no. cs-4970; 1:1,000; both Cell Signaling Technology, Inc., Danvers, MA, USA). $\beta$-Actin was used as loading control. The secondary antibodies were horse anti-mouse immunoglobulin (Ig)G or goat anti-rabbit IgG conjugated to horseradish peroxidase (HRP) (cat. nos. 7076 and 7074, respectively; 1:2,000; Cell Signaling Technology, Inc.). Immobilon Western Chemiluminescent HRP Substrate (cat. no. WBKLS0500) was purchased from Merck KGaA. The integrated density of each band was normalized to the density of corresponding $\beta$-actin.

Growth curve assay. Growth curves were measured by MTT assay as previously described (14). To compare cell proliferation ability underhypoxia or normoxia, cells were cultured with or without $\mathrm{CoCl}_{2}$. The medium were refreshed at the 4th day. Data were collected at 1, 3, 5, and 7 days by measuring the absorbance at $490 \mathrm{~nm}$.

Cisplatin treatment. Cells were treated with cisplatin (Hansoh Pharma, Lianyungang, Jiangsu, China) and $\mathrm{CoCl}_{2}$ for $48 \mathrm{~h}$ at $37^{\circ} \mathrm{C}$. The half-maximal inhibitory concentration $\left(\mathrm{IC}_{50}\right)$ was measured by MTT assay according to procedures described previously (15). The concentration of cisplatin used included $1,10,100$ and $1,000 \mu \mathrm{M}$ for the primary screening for approximate ranges of $\mathrm{IC}_{50}$, and 20,30, 40, 50,60, 70, 80,90 and $100 \mu \mathrm{M}$ for the final evaluation of $\mathrm{IC}_{50}$. For apoptosis analysis, cells were treated with cisplatin at the approximate concentration of $\mathrm{IC}_{50}\left(100 \mu \mathrm{M}\right.$ for SNU601 and $50 \mu \mathrm{M}$ for MKN28) and $\mathrm{CoCl}_{2}$ for $48 \mathrm{~h}$ prior to flow cytometry. Apoptosis was assessed by Annexin V-PE-7AAD (cat. no. 559763; BD Pharmingen; BD Biosciences, San Jose, CA, USA) following the protocol described previously (15).

Cell migration and invasion assay. To evaluate cell migration, wound-healing assays were performed as previously described (16). The widths of the wounds were measured at $72 \mathrm{~h}$ following scratching. The 24-well Transwell chamber with $8-\mu \mathrm{m}$ pore and Matrigel (Corning, Inc., Corning, NY, USA) were used for evaluating cell invasion as previously described (16). Cells were incubated with $\mathrm{CoCl}_{2}$ in the two assays.

Xenograft tumors in nude mice. A total of 20 mice (BALB/c athymic nude mice; age, 4-6 weeks; weight, 15-20 g; sex ratio, 1:1) were purchased from, and also treated and maintained in Shanghai Experimental Animal Center, Chinese Academy of Sciences (Shanghai, China). The mice were maintained in the animal facility in individually ventilated cages in specific pathogen-free conditions in a temperature of $18-29^{\circ} \mathrm{C}$ and humidity of $40-70 \%$, with a 12-h light/dark cycle, and received food and water ad libitum. The animal experiments were approved by the Institutional Animal Care and Use Committee of Chinese Academy of Sciences and performed following institutional guidelines and protocols. To observe the effects of STC1 on tumor growth in vivo, SNU601-STC1 and SNU601-Vec cells were used to generate xenograft tumors on mice. A total of $8 \times 10^{6}$ cells were subcutaneously injected into each mouse ( 4 mice for each cell line). The longest diameter ' $a$ ' and the shortest diameter ' $b$ ' of tumors were measured and the tumor volume was calculated with the use of the following formula: Tumor volume (in $\mathrm{mm}^{3}$ ) $=\mathrm{axb}^{2} \mathrm{x} 0.52$ (14). To observe the effects of STC1 on peritoneal metastasis in vivo, $1 \times 10^{7}$ cells were injected into the peritoneal cavity of every mouse (six mice for each cell line). When the volume of subcutaneous tumor reached $1,500 \mathrm{~mm}^{3}$, mice were sacrificed. All the subcutaneous tumor and peritoneal cancerous nodes were excised and weighed.

Online data analysis. Data from the large online public database Kaplan-Meier Plotter ( $\mathrm{n}=876$; http://kmplot.com/analysis/) was analyzed on the website with the three different probes (204595_s_at, 204596_s_at and 204597_x_at) using the auto select best cut-off (17). 
Table I. Clinical characteristics of patients with different levels of stanniocalcin-1 protein in gastric cancer tissue.

\begin{tabular}{|c|c|c|c|c|c|}
\hline \multirow[b]{2}{*}{ Features } & \multicolumn{2}{|c|}{ Low } & \multicolumn{2}{|c|}{ High } & \multirow[b]{2}{*}{ P-value } \\
\hline & Patients, $\mathrm{n}$ & $(\%)$ & Patients, $\mathrm{n}$ & $(\%)$ & \\
\hline Total & 17 & & 49 & & \\
\hline Age, years & & & & & 0.567 \\
\hline$<60$ & 8 & 12 & 27 & 41 & \\
\hline$\geq 60$ & 9 & 14 & 22 & 33 & \\
\hline Sex & & & & & 0.842 \\
\hline Male & 11 & 17 & 33 & 50 & \\
\hline Female & 6 & 9 & 16 & 24 & \\
\hline Histologic grade & & & & & 0.030 \\
\hline$<$ III & 9 & 14 & 12 & 18 & \\
\hline$\geq \mathrm{III}$ & 8 & 12 & 37 & 56 & \\
\hline Nerve/vascular invasion & & & & & 0.578 \\
\hline Negative & 13 & 20 & 34 & 52 & \\
\hline Positive & 4 & 6 & 15 & 23 & \\
\hline T stage & & & & & 0.958 \\
\hline $\mathrm{T} 1 / 2$ & 2 & 3 & 6 & 9 & \\
\hline $\mathrm{T} 3 / 4$ & 15 & 23 & 43 & 65 & \\
\hline $\mathrm{N}$ stage & & & & & 0.092 \\
\hline No & 7 & 11 & 10 & 15 & \\
\hline $\mathrm{N} 1 / 2 / 3$ & 10 & 15 & 39 & 59 & \\
\hline M stage & & & & & 0.130 \\
\hline M0 & 17 & 26 & 43 & 65 & \\
\hline M1 & 0 & 0 & 6 & 9 & \\
\hline TNM stage & & & & & 0.021 \\
\hline $\mathrm{I} / \mathrm{II}$ & 11 & 17 & 16 & 24 & \\
\hline III/IV & 6 & 9 & 33 & 50 & \\
\hline
\end{tabular}

T, tumor; N, node; M, metastasis; TNM, tumor-node-metastasis.

Immunohistochemical (IHC) staining and analysis. IHC assay were performed on a tissue microarray containing samples from GC patients (HStm-Ade180Sur-06; Outdo Biotech Co., Ltd., Shanghai, China). All procedures were in accordance with the 1964 Declaration of Helsinki and its later amendments. All patients received surgery between August 2008 and March 2009. Excluding patients older than 70 years, 66 patients (28-70 years old) with follow-up information remained in the cohort. The clinical characteristics of patients are presented in Table I. The pathological stage was evaluated according to 7th American Joint Committee on Cancer staging system (18).

STC1 protein expression was detected by IHC staining, and the adjacent section was stained with hematoxylin-eosin and evaluated by two pathologists. The staining and scoring system was performed as previously described (4). The primary antibody against STC1 (N15; sc-14346; Santa Cruz Biotechnology, Inc.) was applied at a dilution of 1:200 and incubated in a humid chamber at $4{ }^{\circ} \mathrm{C}$ overnight. The staining intensity was evaluated as follows: Low, negative or $\leq 40 \%$ weak staining; High, $>40 \%$ cells weak staining, or any cells with moderate or strong staining).
Statistical analysis. Data expressed as the mean \pm standard deviation (SD) of three independently repeated experiments. Error bars in all graphs present the SD. Student's t-test was used to evaluate the difference between every two different groups. A Pearson $\chi^{2}$ test was used to evaluate the association between different clinicopathological characteristics of patients. A Kaplan-Meier log-rank test was used to analysis the survival of patients. $\mathrm{P}<0.05$ was considered to indicate a statistically significant difference. SPSS 16.0 (SPSS, Inc., Chicago, IL, USA) was used to perform the analysis.

\section{Results}

Elevated STC1 is associated with poor survival in GC. To examine the potential role of STC1 in patients with GC, we first investigated the large online database Kaplan-Meier Plotter. It was demonstrated that with different probes, higher expression of STC1 mRNA was associated with worse overall survival (OS) and first progression (FP) in patients with GC (Fig. 1A-F). 
A

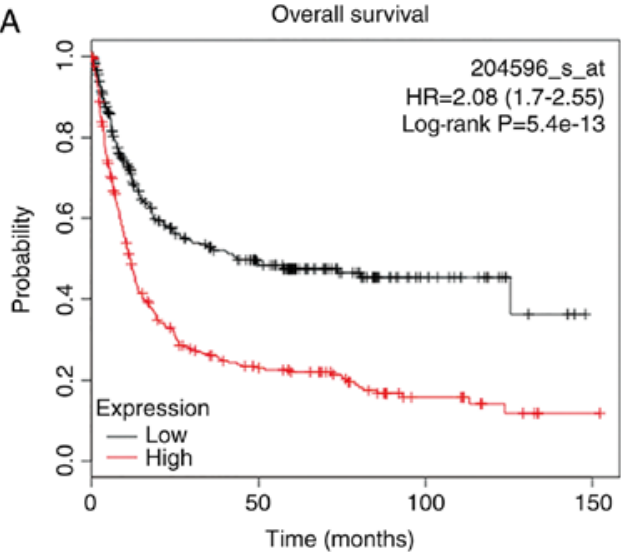

C

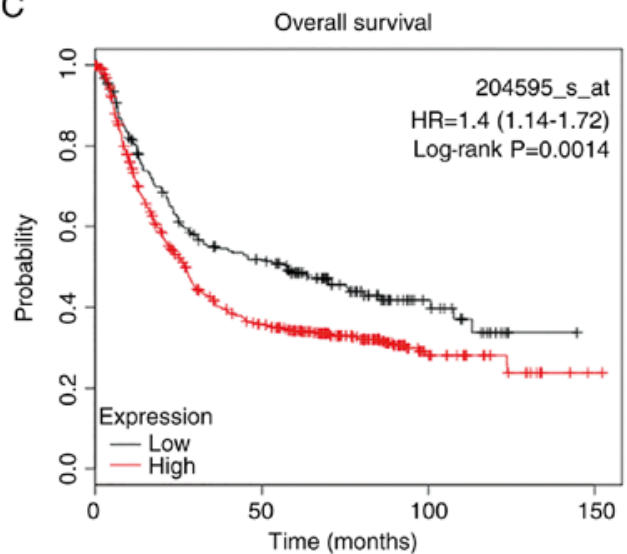

E

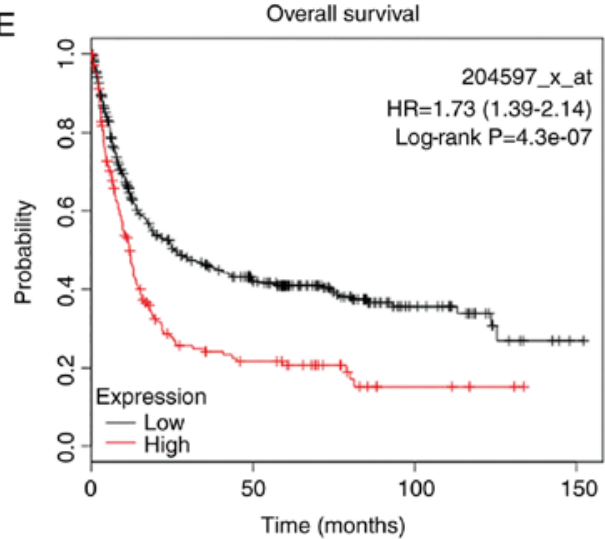

G

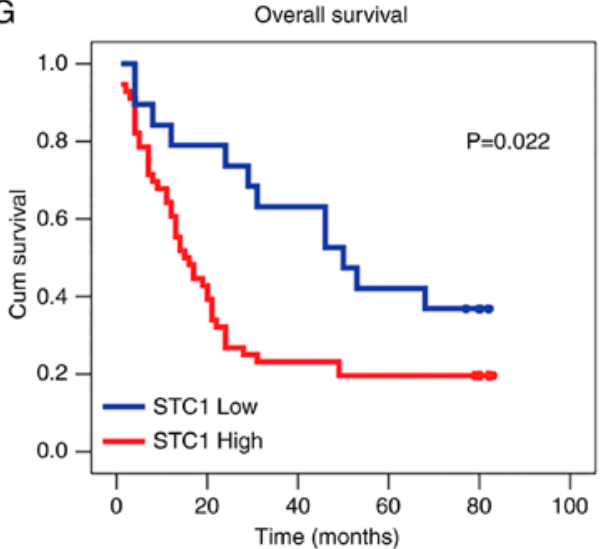

B

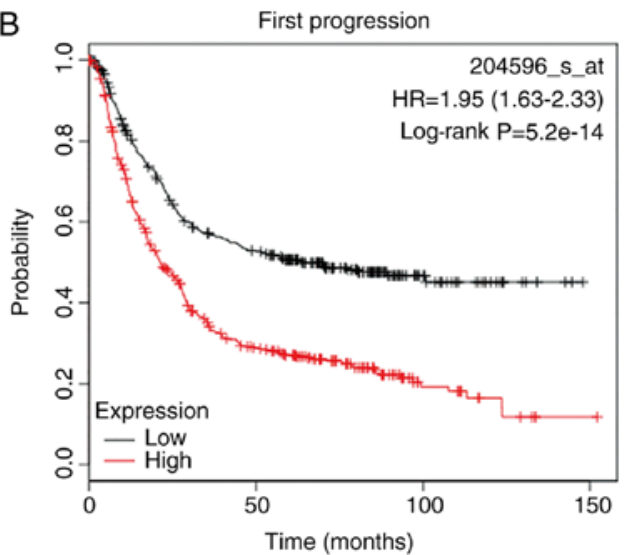

D

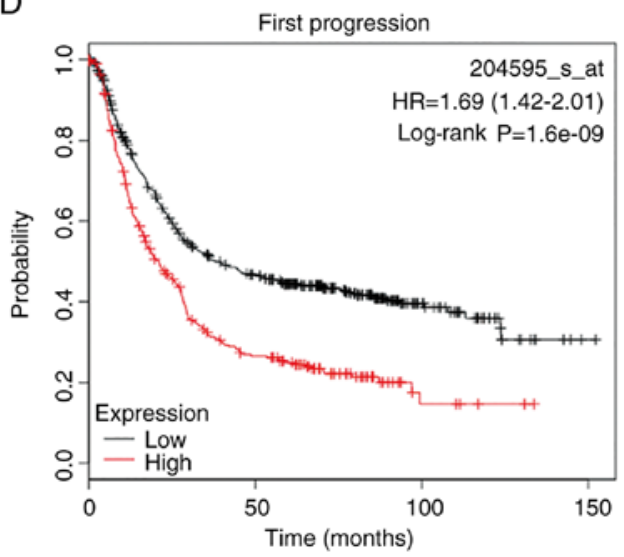

F

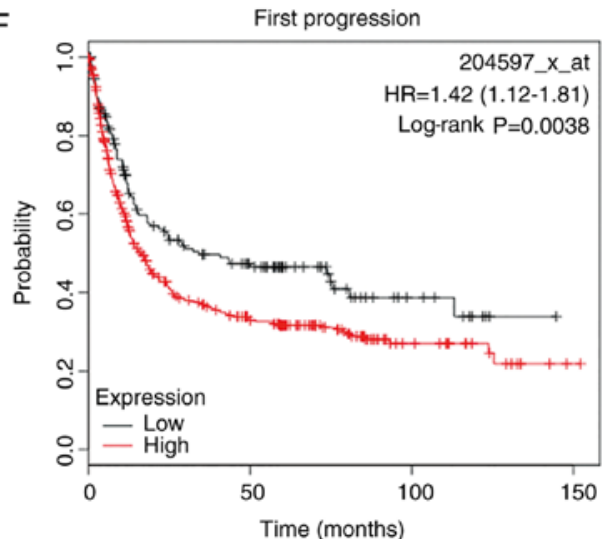

$\mathrm{H}$

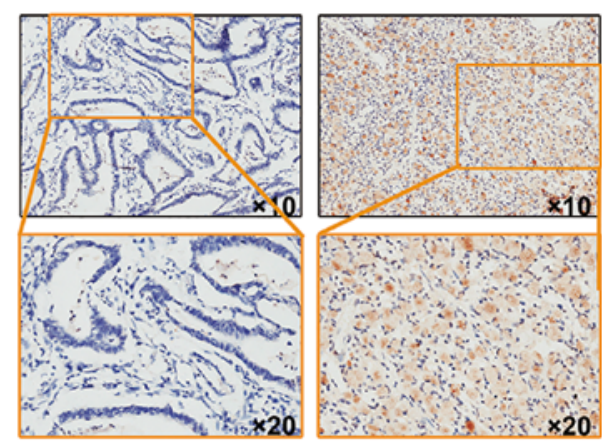

Figure 1. Overexpression of STC1 is associated with poor prognosis in patients with GC. (A-F) Kaplan-Meier analysis of the OS and FP of patients with GC according to STC1 mRNA level on http://kmplot.com/analysis/ using indicated probes (204596_s_at, 204595_s_at, 204597_s_at) with the auto select best cut-off. Black lines and red lines indicated low levels and high levels of STC1, respectively. (G) Kaplan-Meier analysis of the OS in patients with GC according to STC1 protein level. (H) Representative images of low (left) and high (right) levels of STC1 protein in GC tissues in immunohistochemistry analysis. OS, overall survival; GC, gastric cancer; FP, first progression; STC1, stanniocalcin-1; HR, hazard ratio. 
A

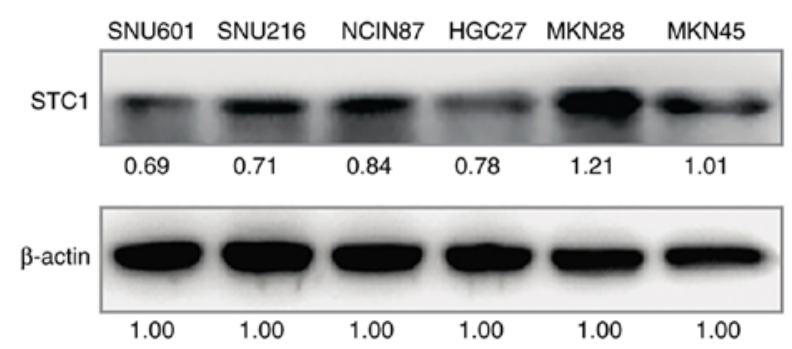

B
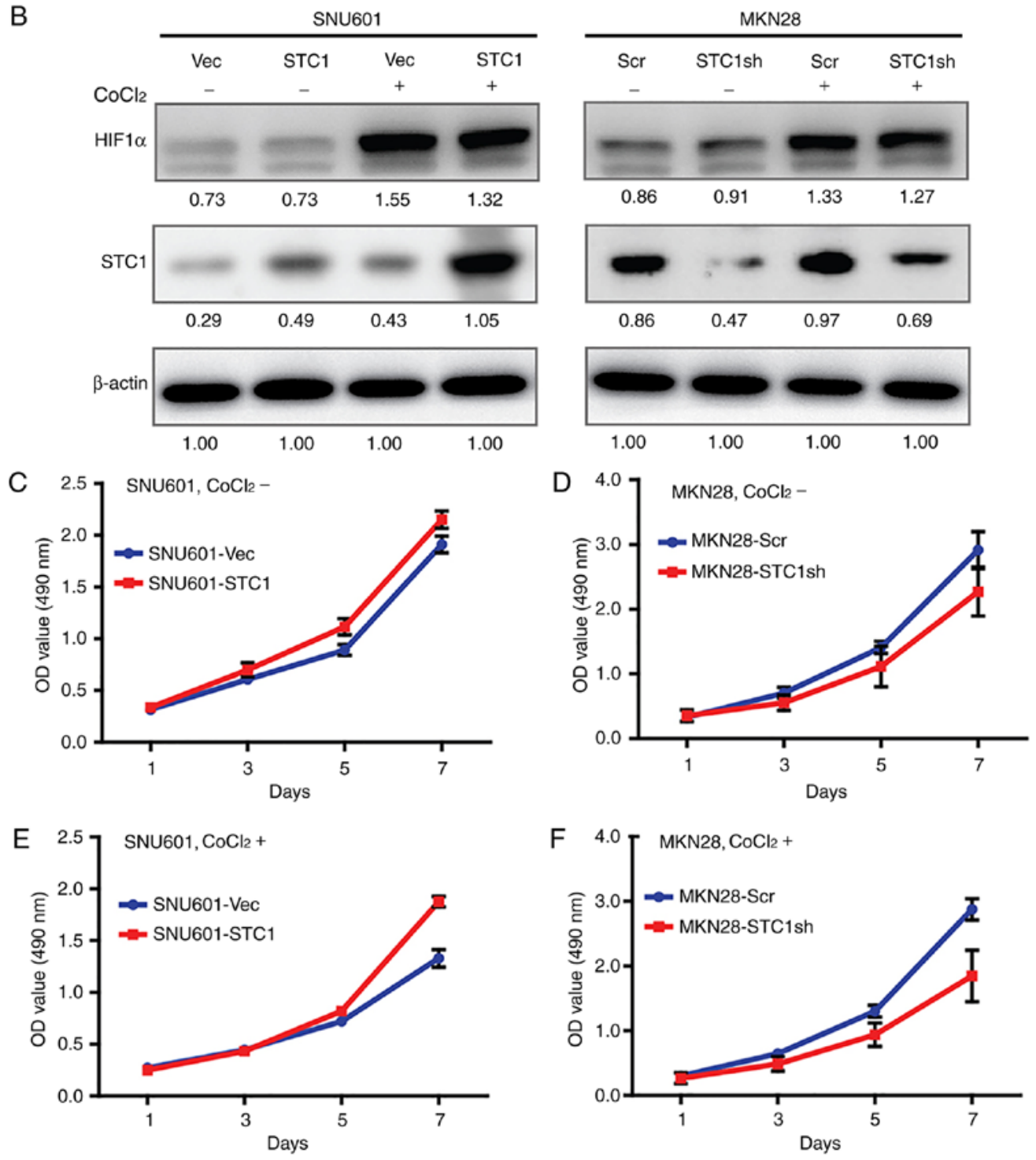

Figure 2. Hypoxia-induced STC1 promotes cell proliferation and chemoresistance in hypoxic GC cells. (A) The basic expression level of STC1 in a number of GC cells. (B) Hypoxia enhanced the expression of STC1 in SNU601 cells and MKN28 cells. $\mathrm{CoCl}_{2}$ was used as a hypoxia mimetic agent. The hypoxia environment was indicated by the increased expression of HIF1- $\alpha$. $\beta$-actin was used as loading control. The number below each band indicates the integrated density normalized to the density of corresponding $\beta$-actin. Growth curves of SNU601 cells and MKN28 cells in (C and D) normoxia and (E and F) hypoxia.

To further validate the association between STC1 and prognosis, IHC staining was used to evaluate the expression of the STC1 protein in tissue samples from GC. The clinicopathological characteristics of patients are summarized in Table I. Higher expression of STC1 in cancer tissue was associated with worse OS ( $\mathrm{P}=0.033$; Fig. $1 \mathrm{G}$ and $\mathrm{H})$. Additionally, correlation analysis indicated that higher levels of STC1 in cancer tissue was associated with poorer differentiation $(\mathrm{P}=0.030)$ and more advanced tumor node and metastasis stages $(\mathrm{P}=0.021$; Table I).
Collectively, these results suggested that overexpression of STC1 was associated with poor prognosis in patients with GC.

Expression of STC1 is enhanced in hypoxic GC cells. To investigate the roles of STC1 in GC in vitro, the expression of STC1 in a set of GC cell lines was screened (Fig. 2A). In the cells which expressed the lowest level of STC1 (SNU601), STC1 cDNA and the vector control was overexpressed; while in the cells which expressed the highest level of STC1 (MKN28), the expression of STC1 was knocked down with shRNA (Fig. 2B). 
G

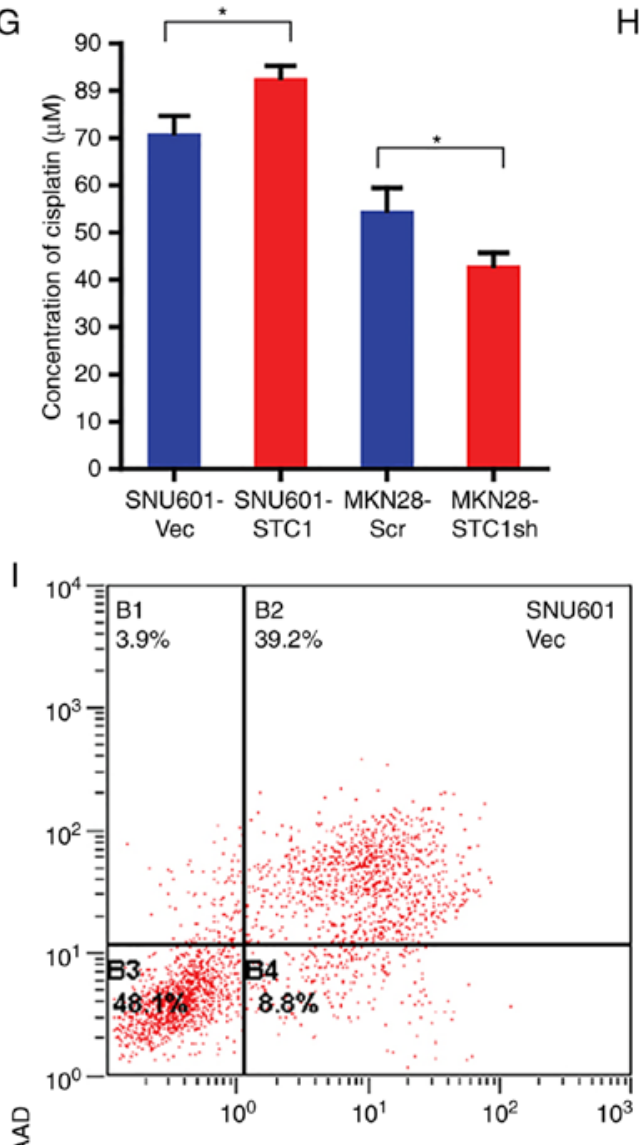

운

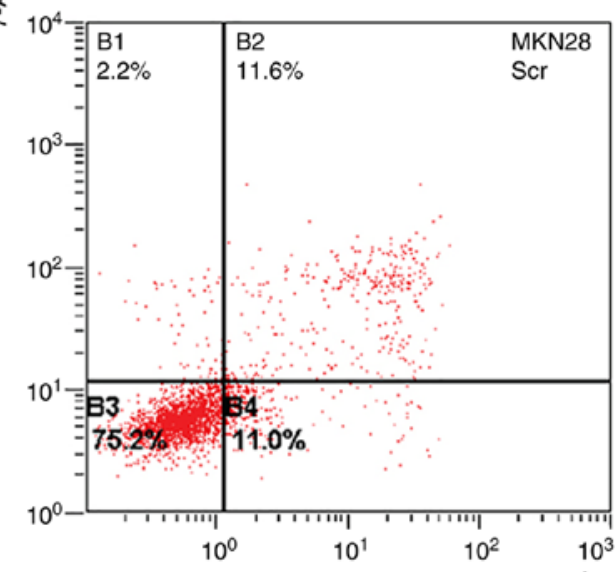

$\mathrm{H}$
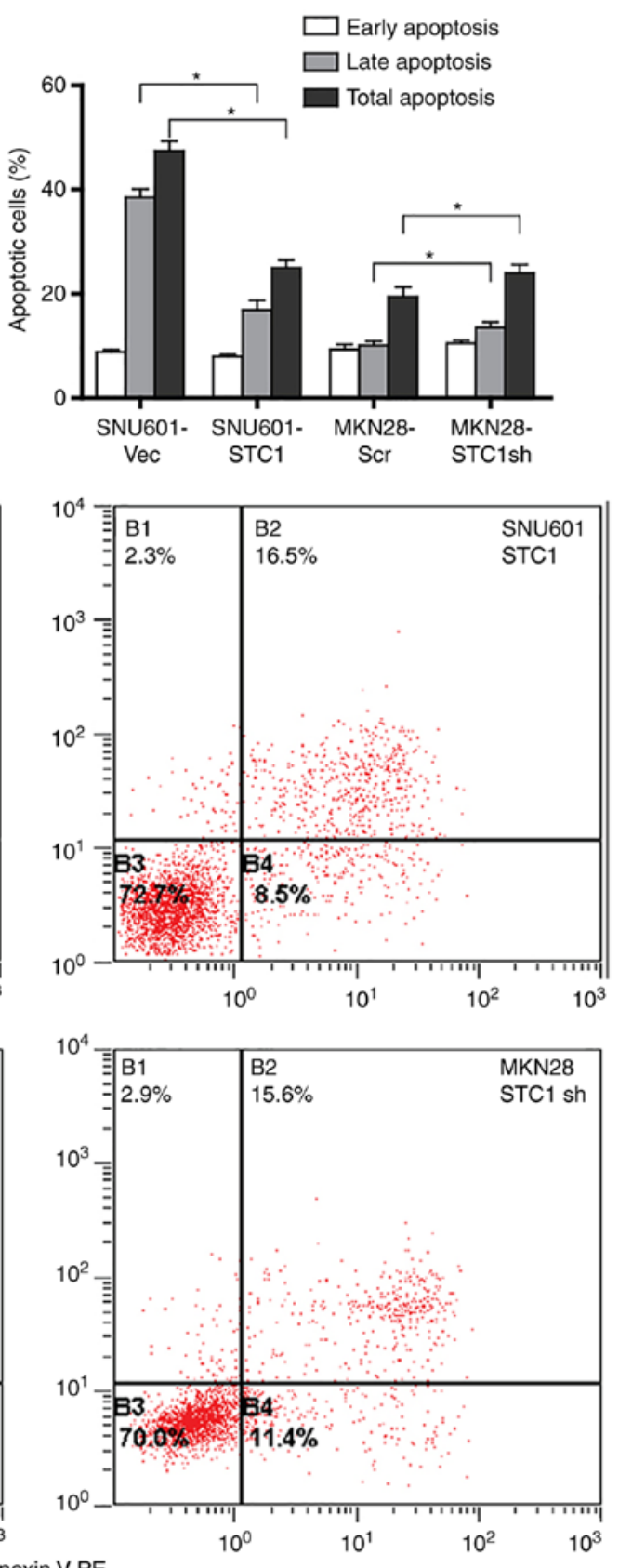

Figure 2. Continued. (G) $\mathrm{IC}_{50}$ of cisplatin and (H) cell apoptosis in response to cisplatin treatment in hypoxic cells. (I) Representative images of cell apoptosis. "P<0.05. GC, gastric cancer; HIF, hypoxia inducible factor; STC1, stanniocalcin-1; Vec, empty vector; sh, small hairpin RNA; OD, optical density; Scr, scramble shRNA.

$\mathrm{CoCl}_{2}$ was used, which inhibits the activity of the key enzyme in the oxygen-sensing pathway (19), to stimulate hypoxia. Results from immunoblotting analysis demonstrated that the expression of HIF1- $\alpha$, the well-established marker of hypoxia (20), increased in cells treated with $\mathrm{CoCl}_{2}$, indicating that the hypoxic environment had been successfully mimicked in vitro (Fig. 2B). Furthermore, the levels of STC1 in hypoxic cells were always increased compared with the same cell lines in normoxic conditions (Fig. 2B), indicating that STC1 may serve certain roles in hypoxic cells.

STC1 promotes cell proliferation and chemoresistance in hypoxia. Previous studies demonstrated that STC1 promoted cell proliferation in a series of cancer cells $(4,6,21)$ : However, the effects of STC1 on cell growth in normoxic or hypoxic GC cells have not been reported, to the best of our knowledge. In the present study, in cells cultured with normal medium the growth curves of SNU601-STC1 cells and SNU601-Vec cells could not be distinguished clearly (Fig. 2C), as well as the curves of MKN28-STC1sh cells and MKN28-Scr cells (Fig. 2D). However, when cells were co-cultured with $\mathrm{CoCl}_{2}, \mathrm{SNU601-STC1}$ cells proliferated more compared with the SNU601-Vec cells (Fig. 2E), while MKN28-STC1sh cells grew more slowly than MKN28-Scr cells (Fig. 2F). The results indicated that overexpression of STC1 promoted cell proliferation in GC cells in hypoxia but not in normoxia. 


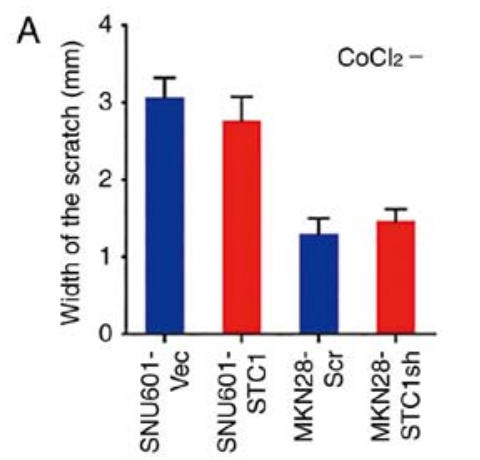

B

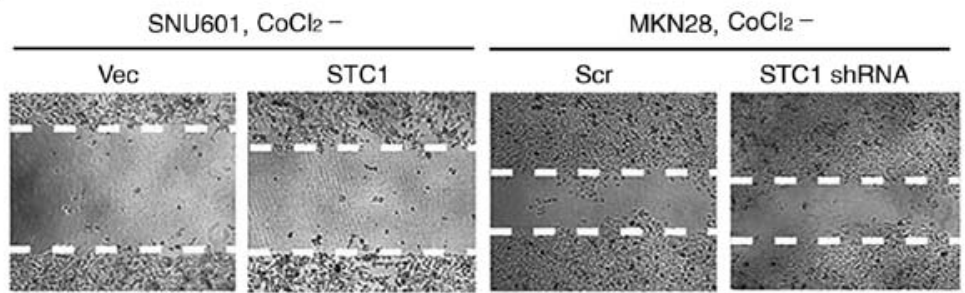

C

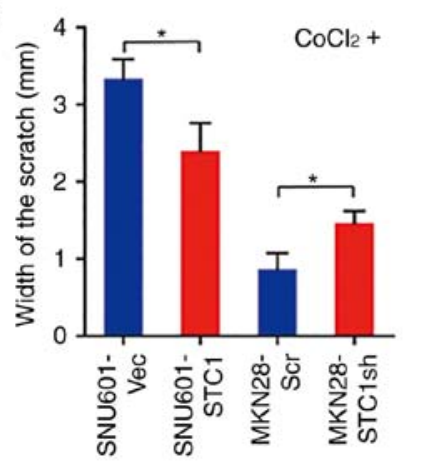

D
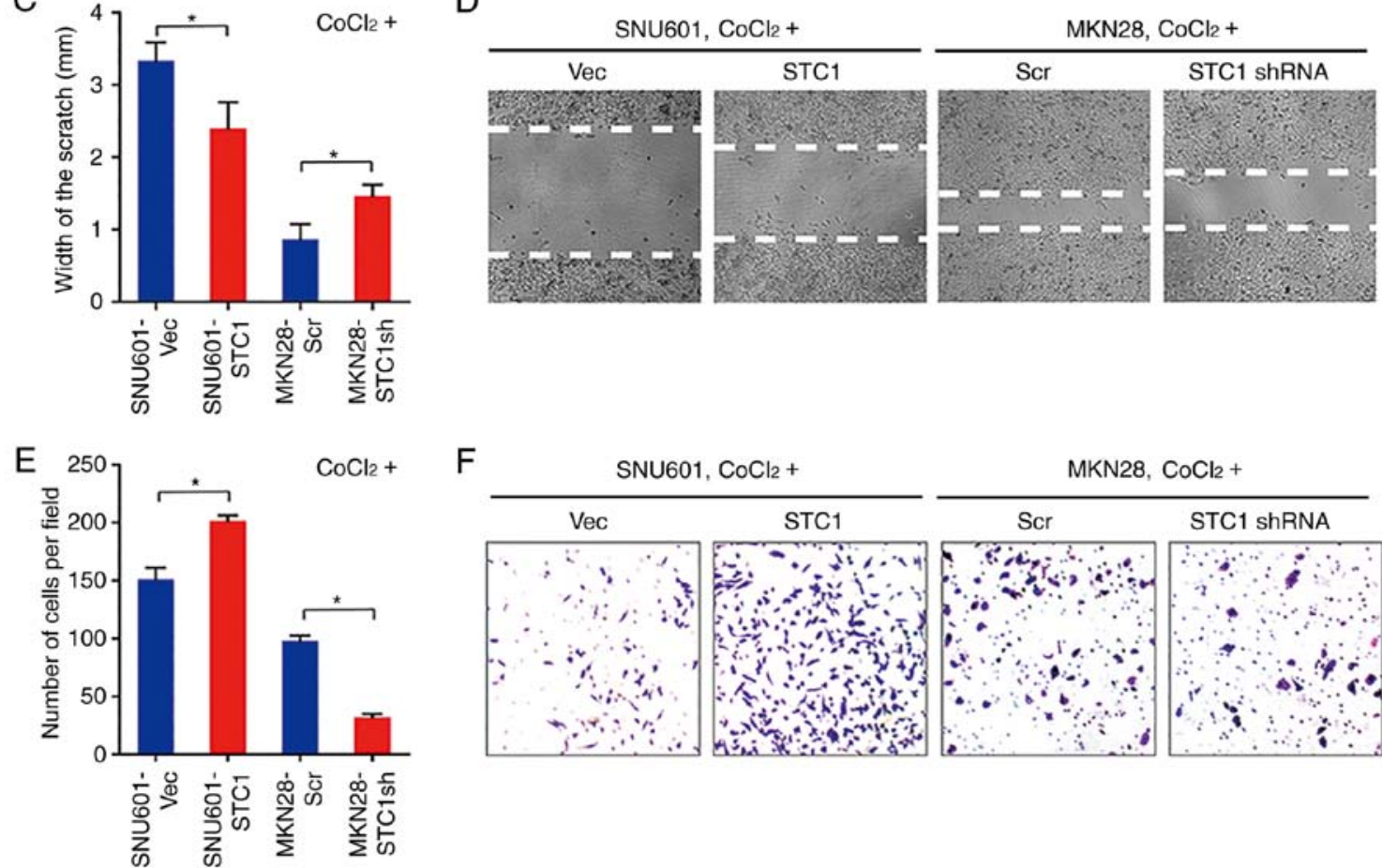

$\mathrm{F}$

SNU601, $\mathrm{CoCl}_{2}+$

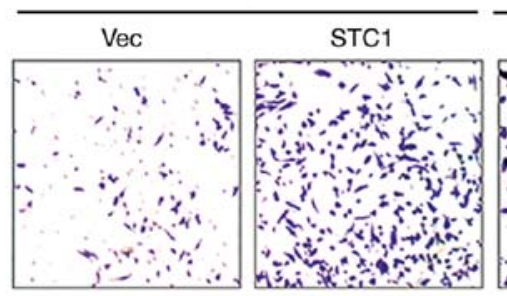

$\mathrm{MKN} 28, \mathrm{CoCl}_{2}+$

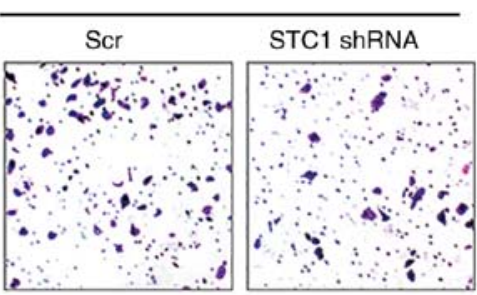

Figure 3. STC1 promotes migration and invasion in hypoxic GC cells. Quantification and representative images of wound widths at $72 \mathrm{~h}$ following scratching in migration assays in SNU601 and MKN28 cells in (A and B) normoxia and (C and D) hypoxia. (E) Numbers of cells invaded through Transwell chambers at $72 \mathrm{~h}$ following seeding in invasion assays in SNU601 cells and MKN28 cells in hypoxia. (F) Representative images of cell invasion (magnification, $\mathrm{x} 20$ ). CoCl ${ }_{2}$ was used as hypoxia mimetic agent. ${ }^{~} \mathrm{P}<0.05$. STC1, stanniocalcin-1; GC, gastric cancer; Vec, empty vector; sh, small hairpin RNA; Scr, scramble shRNA.

The influence of STC1 on chemoresistance in GC was measured further and the influence of STC1 on the cell response to cisplatin in a hypoxic environment was focused on. Results from $\mathrm{IC}_{50}$ (Fig. 2G) and flow cytometry (Fig. 2H-I) demonstrated that, in hypoxic SNU601-STC1 cells, the $\mathrm{IC}_{50}$ of cisplatin was $\sim 82 \mu \mathrm{M}$, and the proportions of late and total apoptotic cells were 16.9 and $25.0 \%$, respectively. However, in hypoxic SNU601-Vec cells, the $\mathrm{IC}_{50}$ of cisplatin was only $71 \mu \mathrm{M}$, and the ratio of cells in late and total apoptosis was 38.5 and $47.4 \%$, respectively. Furthermore, compared with MKN28-Scr cells, the $\mathrm{IC}_{50}$ of MKN28-STC1sh cells was decreased by $16 \%$, and the percentage of late and total apoptotic cells was improved by 33 and 23\%, respectively. Therefore, enhanced expression of STC1 facilitated the resistance to cisplatin treatment in hypoxic GC cells.

STC1 accelerates hypoxia-induced cell migration and invasion. To elucidate the roles of STC1 in cell migration in GC, wound-healing assays were performed in normoxia and hypoxia. At $72 \mathrm{~h}$ following scratching, in cells cultured without $\mathrm{CoCl}_{2}$ the widths of wounds in SNU601-STC1 cells were slightly narrower than in SNU601-Vec cells, and the widths in MKN28-STC1sh cells were wider compared with the MKN28-Scr cells but the change was not statistically significant (Fig. 3A and B). However, in cells treated with $\mathrm{CoCl}_{2}$, the wounds in SNU601-STC1 cells were almost healed, while those in SNU601-Vec cells remained large (Fig. 3C and D). Similarly, the gaps in hypoxic MKN28-STC1sh cells were obviously wider compared with the control cells (Fig. 3C and D). The results suggested that overexpression of STC1 promotes cell migration in hypoxia, but not in normoxia.

Therefore, the function of STC1 on cell invasion under hypoxic conditions was further investigated. At $72 \mathrm{~h}$ following seeding, there were $33 \%$ more cells invading through the gel in SNU601-STC1 cells compared within control cells, while there were $60 \%$ fewer cells moving into the bottom chamber in MKN28-STC1sh cells compared with in MKN28-Scr cells (Fig. 3E and F). Collectively, in hypoxic GC cells, higher levels of STC1 facilitated cell invasion. 
A

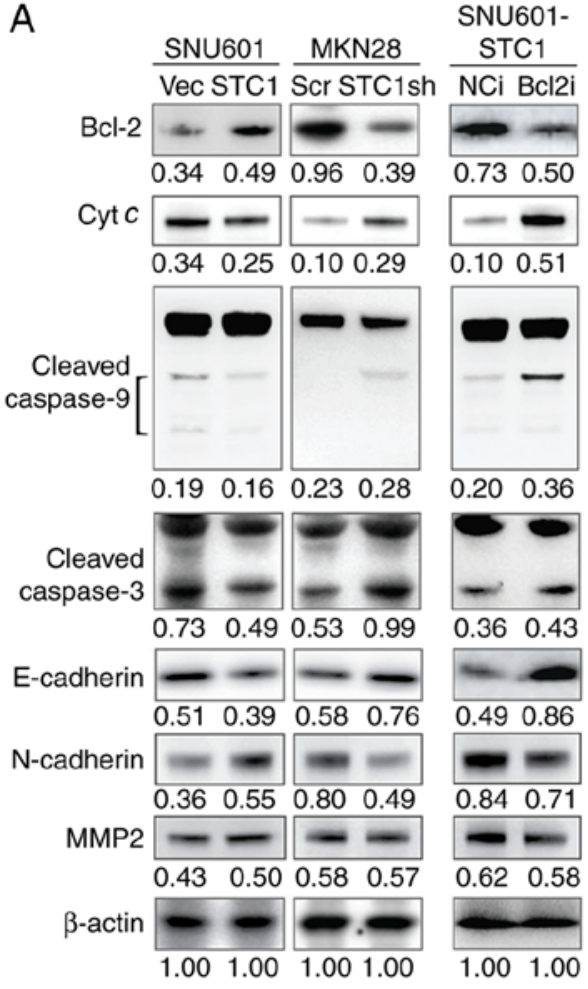

C
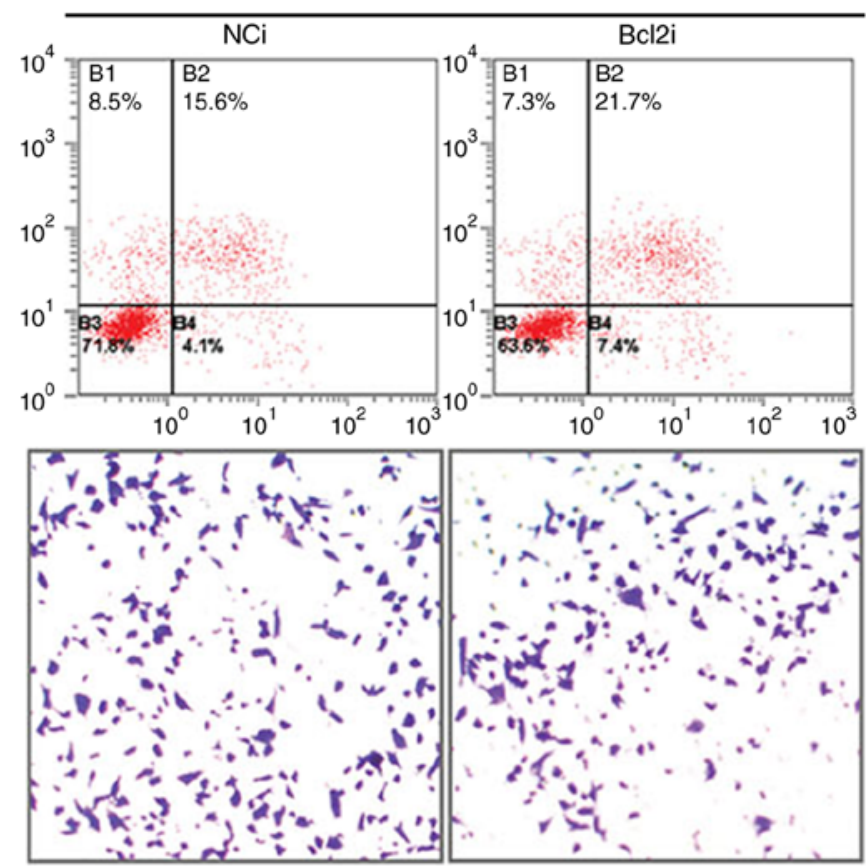

B

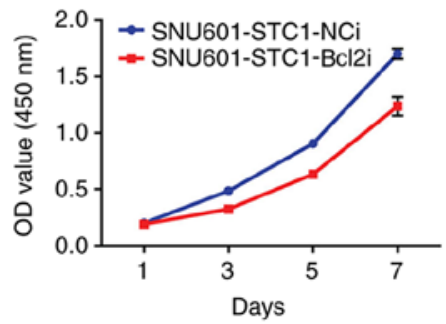

D

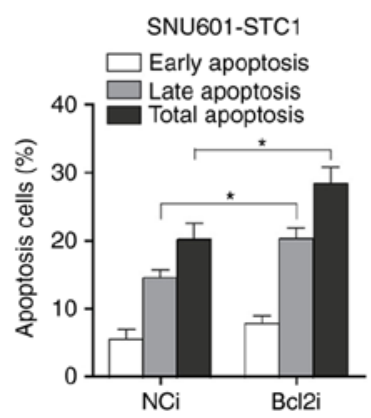

E

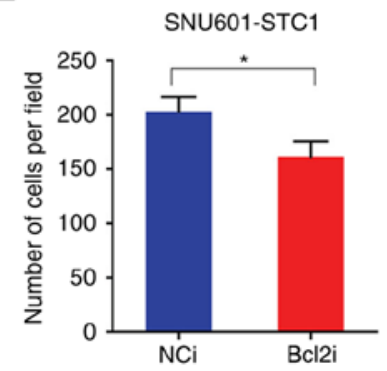

Figure 4. STC1 inhibits apoptosis and promotes invasion via Bcl-2. (A) Immunoblotting analysis of the protein levels of Bcl-2, Cyt $c$, cleaved-caspase-9, cleaved-caspase-3, E-cadherin, N-cadherin, and MMP2. For caspase-9 and -3, upper bands present procaspase-9 and -3, and lower bands present cleaved-caspase- 9 and -3 . $\beta$-actin was used as loading control. The number below each band indicated the integrated density normalized to the density of corresponding $\beta$-actin. (B) Cell proliferation, (C) representative images of cell apoptosis tested by flow cytometry and cell invasion tested by Transwell assays (magnification, x20). (D) Cell apoptosis in response to cisplatin and (E) cell invasion in cells treated with Bcl-2 siRNA or NC siRNA. All experiments were performed in presence of $\mathrm{CoCl}_{2}$. ${ }^{*} \mathrm{P}<0.05$. NC, negative control; E, epithelial; N, neural; Bcl, B cell lymphoma; MMP, matrix metalloproteinase; STC1, stanniocalcin-1; NC, normal control; siRNA, small interfering RNA; Vec, empty vector; sh, small hairpin RNA; Scr, scramble shRNA; Bcl2i, Bcl-2 siRNA; NCi, normal control siRNA; OD, optical density.

STC1 inhibits apoptosis and promotes invasion via Bcl-2. To investigate the mechanisms of STC1-promoted malignant properties under hypoxic conditions, the expression of key proteins in cells treated with $\mathrm{CoCl}_{2}$ was measured. As presented in Fig. 4A, compared with those in SNU601-Vec cells, the expression of Bcl-2 was increased, while the levels of cytochrome $c$, cleaved-caspase- 9 and cleaved-caspase-3 were decreased in SNU601-STC1 cells. In contrast, compared with the MKN28-Scr cells, the level of Bcl-2 was decreased, but those of cytochrome $c$, cleaved-caspase- 9 and cleaved-caspase- 3 were increased in MKN28-STC1sh cells. On the other hand, compared with corresponding control cells, E-cadherin was downregulated, but N-cadherin and MMP2 were upregulated in SNU601-STC1 cells; whereas E-cadherin was upregulated, but $\mathrm{N}$-cadherin and MMP2 were downregulated in MKN28-STC1sh cells. The expression of XIAP and MMP1 were not markedly changed according to the different expression of STC1 (data not shown). The results indicated that the expression of STC1 was positively associated with that of Bcl-2, N-cadherin and MMP2, but negatively associated with that of cytochrome $c$, cleaved-caspase-9, cleaved-caspase-3 and E-cadherin.

As Bcl-2 is a well-characterized and relatively upstream anti-apoptotic protein, the expression of $\mathrm{Bcl}-2$ was artificially knocked-down with siRNA in SNU601-STC1 cells (Fig. 4A), and the cells' biological behavior was tested under hypoxic conditions. As presented in Fig. 4B-D, in SNU601-STC1$\mathrm{Bcl} 2 \mathrm{i}$ cells, cell proliferation was arrested, and the ratios of apoptotic cells treated with cisplatin were raised in SNU601-STC1-Bcl2i cells. Furthermore, under hypoxic conditions, the expression of cytochrome $c$, cleaved-caspase-9, and cleaved-caspase-3 were upregulated in SNU601-STC1$\mathrm{Bcl} 2 \mathrm{i}$ cells compared with those in control cells (Fig. 4A). As 
A

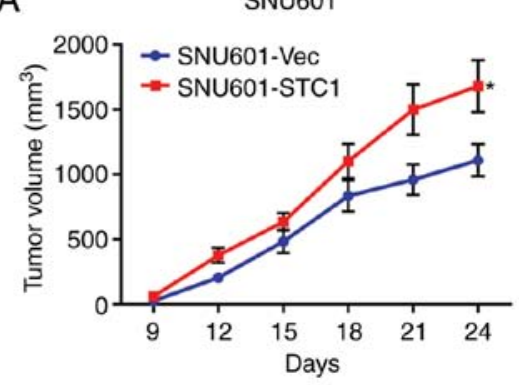

B

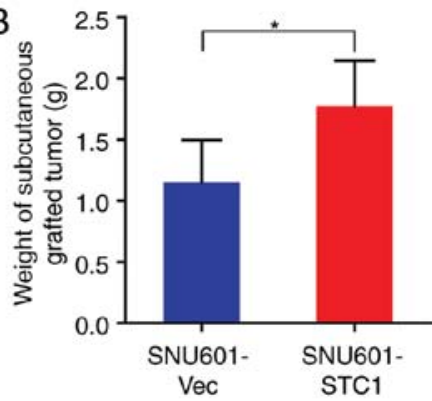

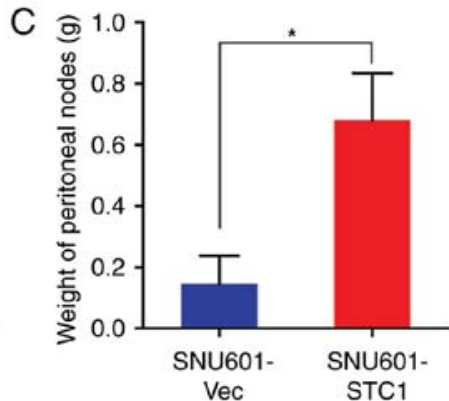

D

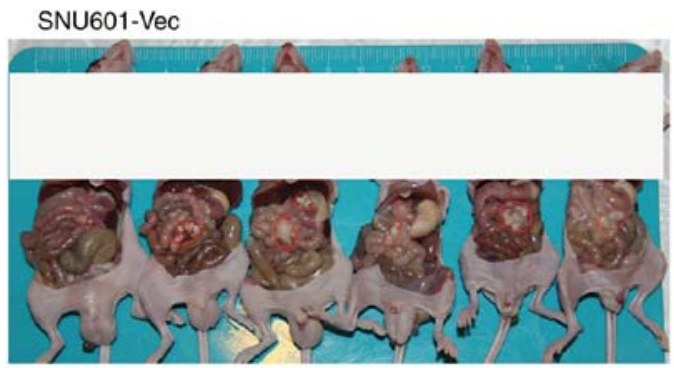

SNU601-STC1

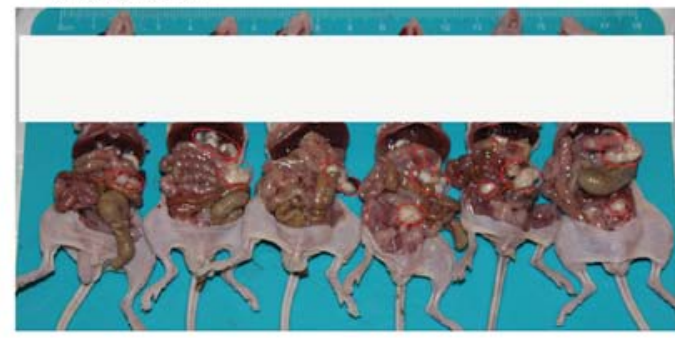

Figure 5. STC1 promotes tumor growth and metastasis in nude mice. (A) Volume of subcutaneous tumors. (B) Mean weights of subcutaneous tumors. (C) Mean weights of total peritoneal nodes in each mouse. (D) Representative images of peritoneal metastasis. ${ }^{*} \mathrm{P}<0.05$. STC1, stanniocalcin-1; Vec, empty vector.

Bcl-2 was also involved in the process of epithelial-mesenchymal transition (EMT) $(13,22,23)$, the invasive ability of SNU601-STC1-Bcl2i cells was also measured. The results demonstrated that the numbers of cells invading through the Transwell chamber were decreased, and the expression of E-cadherin was increased, but those of N-cadherin and MMP2 were lower in hypoxic SNU601-STC1-Bcl2i cells compared with in SNU601-STC1-NCi cells (Fig. 4C and E). Therefore, downregulating the expression of Bcl-2 could significantly reverse the aggressive properties induced by STC1.

These results suggest that, in hypoxic GC cells, STC1 may facilitate cell proliferation, chemoresistance and metastasis via Bcl-2.

STC1 promotes tumor growth and metastasis in vivo. To further test the influence of STC1 in vivo, SNU601-STC1 cells and SNU601-Vec cells were injected into nude mice.

As presented in Fig. 5A, the volumes of subcutaneous tumors withSNU601-STC1 cells were increased compared with SNU601-Vec cells, and the disparities increased with time. Furthermore, at the endpoint of the experiments the weight of SNU601-STC1 tumors was increased compared with that of SNU601-Vec tumors (Fig. 5B). Therefore, the results suggested that SNU601-STC1 tumors grow faster than SNU601-Vec tumors.

Additionally the weight of peritoneal masses produced with SNU601-STC1 cells was significantly heavier compared with SNU601-Vec cells (Fig. 5C), indicating that SNU601-STC1 cells caused increased peritoneal metastasis compared with SNU601-Vec cells. Furthermore, the malignant nodules in the abdominal cavity generated with SNU601-STC1 cells were greater in number and larger compared with SNU601-Vec cells (Fig. 5D).

In short, the results implied that overexpression of STC1 promoted gastric tumor growth and metastasis in nude mice in vivo.

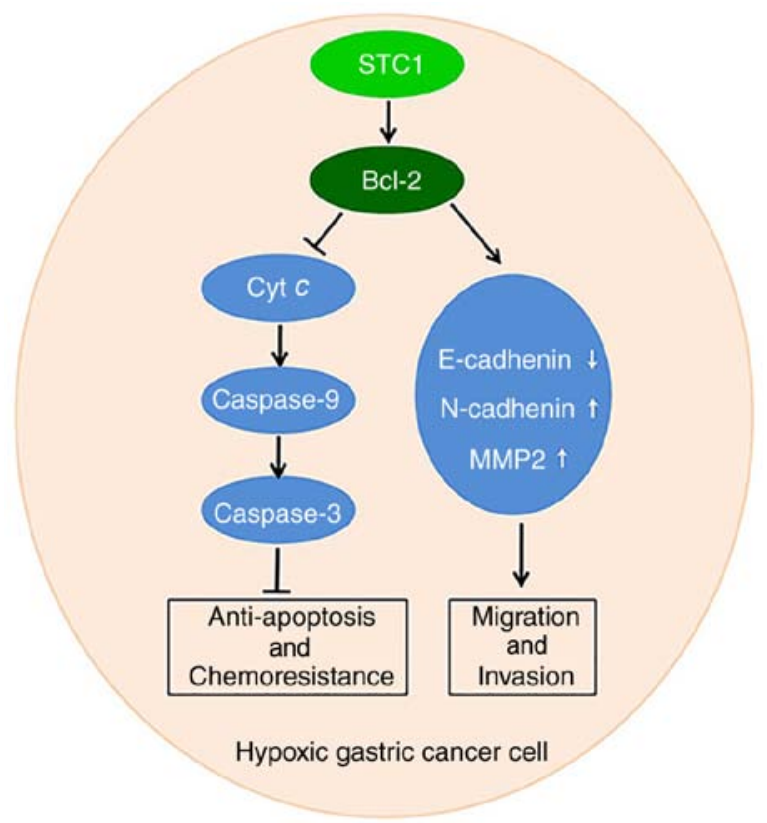

Figure 6. Model of STC1-mediated GC progression in hypoxia. In a hypoxic environment, elevated STC1 promotes the expression of Bcl-2, and restrains the expression of cyt $c$ and the activation of caspase- 9 and caspase- 3 to inhibit apoptosis and further promote cell proliferation and chemoresistance. It also acts to restrain the expression of E-cadherin while increasing the levels of $\mathrm{N}$-cadherin and MMP2 to promote metastasis and invasion. E, epithelial; $\mathrm{N}$, neural; Bcl, B-cell lymphoma; MMP, matrix metalloproteinase; GC, gastric cancer; STC1, stanniocalcin-1; Bcl, B cell lymphoma; cyt $c$, cytochrome $c$.

\section{Discussion}

In the present study, the roles of STC1 in GC were illustrated. It was demonstrated that the higher level of STC1 mRNA and STC1 protein were associated with worse survival of patients with GC. In vitro experiments identified that the expression of STC1 is enhanced in hypoxic GC cells, and that overexpression of STC1 facilitated cell proliferation in hypoxia but not 
in normoxia. Furthermore, STC1 promoted chemoresistance, migration and invasion in hypoxia. Additionally, under hypoxic conditions, the elevated expression of STC1 was associated with an enhanced expression of Bcl-2, N-cadherin and MMP2, and downregulated levels of cytochrome $c$, cleaved-caspase-9, cleaved-caspase-3, and E-cadherin. However, interfering with the expression of Bcl-2 increased the levels of cytochrome $c$, cleaved-caspase-9, cleaved-caspase-3 and E-cadherin, decreased the levels of N-cadherin and MMP2, and further restrained cell proliferation, chemoresistance and cell invasion in hypoxia. In vivo experiments also indicated that STC1 promotes gastric tumor growth and metastasis. Collectively, STC1may promote GC development, chemoresistance and metastasis via Bcl-2 under hypoxic conditions (Fig. 6).

In patients with $\mathrm{GC}$, a previous study reported that the high/moderate level of STC1 protein was associated with poor progression-free survival (7), but the effects of STC1 on OS has not been illustrated. In the present study, according to data in the Kaplan-Meier Plotter database, a higher level of STC1 mRNA was associated with shorter OS and FP. In another cohort or GC patients, it was demonstrated that a higher level of STC1 protein in cancer tissues was associated with poorer differentiation, more advanced clinical stage, and worse OS. The results indicated that overexpression of STC1 may participate in GC progression.

Hypoxia-induced genes make cells more tolerant to the unfavorable conditions in certain cancer cell lines $(24,25)$. In accordance with studies in other cell lines (9,26-29), it was demonstrated that STC1 could be stimulated in hypoxic environments. However, the roles of STC1 under hypoxic conditions are inconsistent according to different cell types. In mouse embryonic fibroblast cells, $S T C 1^{-/-}$cells exhibited greater survival than $\mathrm{STCl}^{+/+}$cells (30). Whereas in rat cardiomyocytes (31) and in mice neural and renal cells $(32,33)$, STC1 serves protective roles. In the present study, it was demonstrated that in GC cell lines, STC1 accelerated cell proliferation in hypoxia but not in normoxia. Enhanced expression of STC1 inhibited cell apoptosis in response to cisplatin treatment in hypoxia.

According to the study by Liu et al (4) in ovarian cancer cells in normoxia, STC1 appears to promote the expression of Bcl-2, a well-characterized protein in apoptosis, leading to caspase-9/-3-dependent cell death. In the present study, it was demonstrated that in hypoxic cells the level of STC1 was positively associated with the expression of $\mathrm{Bcl}-2$, but negatively associated with the levels of down stream cytochrome $c$, cleaved-caspase-9, and the executioner cleaved-caspase-3. Downregulating the expression of $\mathrm{Bcl}-2$ upregulated the levels of cytochrome $c$, cleaved-caspase-9, cleaved-caspase-3, and partly reversed the pro-growth and anti-apoptosis roles of STC1. Furthermore, subcutaneous tumors with enhanced expression of STC1 grew faster, and therefore were larger and heavier compared with the control tumors. Collectively, the results indicated that $\mathrm{STC1}$ may promote the development and chemoresistance of $\mathrm{GC}$ via the Bcl-2-mediated anti-apoptosis pathway in hypoxia.

Several studies have reported that elevated STC1 promoted metastasis in various types of cancer, including $\mathrm{GC}(7,27,34,35)$. However, the studies on GC seldom involved cells in hypoxia. In glioma cells, STC1 promoted cell migration in a hypoxia-dependent manner, but did not exhibit pro-migration abilities under normoxic conditions (36). However, the mechanism was not clear. In the present study, it was demonstrated that overexpression of STC1 facilitated both migration and invasion in hypoxic GC cells. Previously, Bcl-2 was reported to promote EMT and metastasis $(13,37)$. Furthermore, Bcl-2 was also involved in cell metastasis in hypoxia $(38,39)$. In the present study, it was demonstrated that the expression of STC1 was positively associated with that of $\mathrm{Bcl}-2, \mathrm{~N}$-cadherin and MMP2, but negatively associated with the level of E-cadherin. Furthermore, restraining the expression of Bcl-2 decreased the level of N-cadherin and MMP2, but increased that of E-cadherin, and partially reversed the invasive potential of STC1 overexpressing cells in hypoxia. Furthermore, cells with elevated levels of STC1 formed an increased number and heavier metastatic nodes inperitoneal cavities compared with control cells. Therefore, the results suggested that under hypoxic conditions STC1 may promote metastasis via restraining the Bcl-2-adjusted EMT process in GC.

In conclusion, the results of the present study indicated that STC1 positively regulated Bcl-2 to promote GC development, chemoresistance and metastasis under hypoxia, and STC1 and Bcl-2 may be considered as potential therapeutic targets in GC.

\section{Acknowledgements}

Not applicable.

\section{Funding}

The present study was supported by the National Natural Science Foundation of China (grant nos. 81502049 for Yan Wang and 81572955 for Zhen Zhang).

\section{Availability of data and materials}

All data generated or analyzed during this study are included in this published article.

\section{Authors' contributions}

YW, ZQ, MZ, WY, RH and GL performed the experiments on cells and mice, the database analysis and IHC analysis. YW, XM and ZZ designed the experiments. YW drafted the manuscript. XM and ZZ edited the manuscript. All authors read and approved the final manuscript.

\section{Ethics approval and consent to participate}

The animal experiments were approved by the Institutional Animal Care and Use Committee of Chinese Academy of Sciences (Beijing, China). The use of human tissues was approved by the Ethics Committee of Outdo Biotech Co., and the cooperating hospitals and written informed consent was obtained from all patients.

\section{Patient consent for publication}

Consent for the publication of the clinical and pathological data was obtained from all patients who were involved in the present study. 


\section{Competing interests}

The authors declare that they have no competing interests.

\section{References}

1. Khazaei S, Rezaeian S, Soheylizad M, Khazaei S and Biderafsh A: Global incidence and mortality rates of stomach cancer and the human development index: An ecological study. Asian Pac J Cancer Prev 17: 1701-1704, 2016.

2. Sullivan R and Graham CH: Hypoxia-driven selection of the metastatic phenotype. Cancer Metastasis Rev 26: 319-331, 2007.

3. Vaupel P and Mayer A: Hypoxia in cancer: Significance and impact on clinical outcome. Cancer Metastasis Rev 26: 225-239, 2007.

4. Liu G, Yang G, Chang B, Mercado-Uribe I, Huang M, Zheng J, Bast RC, Lin SH and Liu J: Stanniocalcin 1 and ovarian tumorigenesis. J Natl Cancer Inst 102: 812-827, 2010.

5. Tamura S, Oshima T, Yoshihara K, Kanazawa A, Yamada T, Inagaki D, Sato T, Yamamoto N, Shiozawa M, Morinaga S, et al: Clinical significance of STC1 gene expression in patients with colorectal cancer. Anticancer Res 31: 325-329, 2011.

6. Chang AC, Doherty J, Huschtscha LI, Redvers R, Restall C, Reddel RR and Anderson RL: STC1 expression is associated with tumor growth and metastasis in breast cancer. Clin Exp Metastasis 32: 15-27, 2015.

7. Fang Z, Tian Z, Luo K, Song H and Yi J: Clinical significance of stanniocalcin expression in tissue and serum of gastric cancer patients. Chinese J Cancer Res 26: 602-610, 2014

8. Zhang K, Lindsberg PJ, Tatlisumak T, Kaste M, Olsen HS and Andersson LC: Stanniocalcin: A molecular guard of neurons during cerebral ischemia. Proc Natl Acad Sci USA 97: 3637-3642, 2000.

9. Yeung HY, Lai KP, Chan HY, Mak NK, Wagner GF and Wong CK: Hypoxia-inducible factor-1-mediated activation of stanniocalcin-1 in human cancer cells. Endocrinology 146: 4951-4960, 2005.

10. Shroff EH, Snyder C and Chandel NS: Bcl-2 family members regulate anoxia-induced cell death. Antioxid Redox Signal 9: $1405-1409,2007$.

11. Liu L, Ning X, Sun L, Zhang H, Shi Y, Guo C, Han S, Liu J, Sun S, Han Z, et al: Hypoxia-inducible factor-1 alpha contributes to hypoxia-induced chemoresistance in gastric cancer. Cancer Sci 99: 121-128, 2008.

12. Capes-Davis A, Theodosopoulos G, Atkin I, Drexler HG, Kohara A, MacLeod RA, Masters JR, Nakamura Y, Reid YA, Reddel RR, et al: Check your cultures! A list of cross-contaminated or misidentified cell lines. Int J Cancer 127: 1-8, 2010.

13. Sun T, Sun BC, Zhao XL, Zhao N, Dong XY, Che N, Yao Z, Ma YM, Gu Q, Zong WK, et al: Promotion of tumor cell metastasis and vasculogenic mimicry by way of transcription coactivation by Bcl-2 and Twist1: A study of hepatocellular carcinoma. Hepatology 54: 1690-1706, 2011.

14. Wang Y, Wang Z, Qi Z, Yin S, Zhang N, Liu Y, Liu M, Meng J, Zang R,Zhang Z, et al: The negative interplay between Aurora A/B and BRCA $1 / 2$ controls cancer cell growth and tumorigenesis via distinct regulation of cell cycle progression, cytokinesis, and tetraploidy. Mol Cancer 13: 94, 2014.

15. Sun H, Wang Y, Wang Z, Meng J, Qi Z and Yang G: Aurora-A controls cancer cell radio- and chemoresistance via ATM/Chk2-mediated DNA repair networks. Biochim Biophys Acta 1843: 934-944, 2014.

16. Hou J, Wang Z, Xu H, Yang L, Yu X, Yang Z, Deng Y, Meng J, Feng Y, Guo X, et al: Stanniocalicin 2 suppresses breast cancer cell migration and invasion via the PKC/claudin-1-mediated signaling. PLoS One 10: e0122179, 2015.

17. Szasz AM, Lanczky A, Nagy A, Förster S, Hark K, Green JE, Boussioutas A, Busuttil R, Szabó A and Győ́rffy B: Cross-validation of survival associated biomarkers in gastric cancer using transcriptomic data of 1,065 patients. Oncotarget 7: 49322-49333, 2016

18. Wang W, Sun XW, Li CF, Lv L, Li YF, Chen YB, Xu DZ, Kesari R, Huang CY, Li W, et al: Comparison of the 6th and 7th editions of the UICC TNM staging system for gastric cancer: Results of a Chinese single-institution study of 1,503 patients. Ann Surg Oncol 18: 1060-1067, 2011

19. Salnikow K, Donald SP, Bruick RK, Zhitkovich A, Phang JM and Kasprzak KS: Depletion of intracellular ascorbate by the carcinogenic metals nickel and cobalt results in the induction of hypoxic stress. J Biol Chem 279: 40337-40344, 2004
20. Rath S, Anand A, Ghosh N, Das L, Kokate SB, Dixit P, Majhi S, Rout N, Singh SP and Bhattacharyya A: Cobalt chloride-mediated protein kinase Calpha (PKCalpha) phosphorylation induces hypoxia-inducible factor 1alpha (HIF1alpha) in the nucleus of gastric cancer cell. Biochem Biophys Res Commun 471: 205-212, 2016.

21. Bai Y, Xiao Y, Dai Y, Chen X, Li D, Tan X and Zhang X: Stanniocalcin 1 promotes cell proliferation via cyclin E1/ cyclin-dependent kinase 2 in human prostate carcinoma. Oncol Rep 37: 2465-2471, 2017.

22. Zuo J, Ishikawa T, Boutros S, Xiao Z, Humtsoe JO and Kramer RH: Bcl-2 overexpression induces a partial epithelial to mesenchymal transition and promotes squamous carcinoma cell invasion and metastasis. Mol Cancer Res 8: 170-182, 2010.

23. Choi J, Choi K, Benveniste EN, Rho SB, Hong YS, Lee JH, Kim J and Park K: Bcl-2 promotes invasion and lung metastasis by inducing matrix metalloproteinase-2. Cancer Res 65: 5554-5560, 2005.

24. Sumiyoshi Y, Kakeji Y, Egashira A, Mizokami K, Orita H and Maehara Y: Overexpression of hypoxia-inducible factor 1alpha and $\mathrm{p} 53$ is a marker for an unfavorable prognosis in gastric cancer. Clin Cancer Res 12: 5112-5117, 2006.

25. Lu X and Kang Y: Hypoxia and hypoxia-inducible factors: Master regulators of metastasis. Clin Cancer Res 16: 5928-5935, 2010.

26. Lal A, Peters H, St Croix B, Haroon ZA, Dewhirst MW, Strausberg RL, Kaanders JH, van der Kogel AJ and Riggins GJ: Transcriptional response to hypoxia in human tumors. J Natl Cancer Inst 93: 1337-1343, 2001.

27. Ma X, Gu L, Li H, Gao Y, Li X, Shen D, Gong H, Li S, Niu S, Zhang Y, et al: Hypoxia-induced overexpression of stanniocalcin-1 is associated with the metastasis of early stage clear cell renal cell carcinoma. J Transl Med 13: 56, 2015.

28. Law AY, Ching LY, Lai KP and Wong CK: Identification and characterization of the hypoxia-responsive element in human stanniocalcin-1 gene. Mol Cell Endocrinol 314: 118-127, 2010.

29. Cornmark L, Lonne GK, Jogi A and Larsson C: Protein kinase Calpha suppresses the expression of STC1 in MDA-MB-231 breast cancer cells. Tumour Biol 32: 1023-1030, 2011.

30. Nguyen A, Chang AC and Reddel RR: Stanniocalcin-1 acts in a negative feedback loop in the prosurvival ERK1/2 signaling pathway during oxidative stress. Oncogene 28: 1982-1992, 2009.

31. Shi X, Wang J and Qin Y: Recombinant adeno-associated virus-delivered hypoxia-inducible stanniocalcin-1 expression effectively inhibits hypoxia-induced cell apoptosis in cardiomyocytes. J Cardiovasc Pharmacol 64: 522-529, 2014.

32. Westberg JA, Serlachius M, Lankila P, Penkowa M, Hidalgo J and Andersson LC: Hypoxic preconditioning induces neuroprotective stanniocalcin-1 in brain via IL-6 signaling. Stroke 38: 1025-1030, 2007.

33. Liu D, Shang H and Liu Y: Stanniocalcin-1 protects a mouse model from renal ischemia-reperfusion injury by affecting ROS-mediated multiple signaling pathways. Int J Mol Sci 17: E1051, 2016.

34. Arigami T, Uenosono Y, Ishigami S, Hagihara T, Haraguchi N, Matsushita D, Yanagita S, Nakajo A, Okumura H, Hokita S, et al: Expression of stanniocalcin 1 as a potential biomarker of gastric cancer. Oncology 83: 158-164, 2012.

35. He LF, Wang TT, Gao QY, Zhao GF, Huang YH, Yu LK and Hou YY: Stanniocalcin-1 promotes tumor angiogenesis through up-regulation of VEGF in gastric cancer cells. J Biomed Sci 18 : 39, 2011.

36. Yoon JH,Kim J, Kim KL, Kim DH,Jung SJ, Lee H, Ghim J, Kim D, Park JB, Ryu SH, et al: Proteomic analysis of hypoxia-induced U373MG glioma secretome reveals novel hypoxia-dependent migration factors. Proteomics 14: 1494-1502, 2014.

37. An J, Lv J, Li A, Qiao J, Fang L, Li Z, Li B, Zhao W, Chen $\mathrm{H}$ and Wang L: Constitutive expression of Bcl-2 induces epithelial-Mesenchymal transition in mammary epithelial cells. BMC Cancer 15: 476, 2015.

38. Leng J, Song Q, Zhao Y and Wang Z: miR15a represses cancer cell migration and invasion under conditions of hypoxia by targeting and downregulating $\mathrm{Bcl} 2$ expression in human osteosarcoma cells. Int J Oncol 52: 1095-1104, 2018.

39. Duan Y,He Q, Yue K, Si H, Wang J,Zhou X and Wang X: Hypoxia induced $\mathrm{Bcl}-2 /$ Twist1 complex promotes tumor cell invasion in oral squamous cell carcinoma. Oncotarget 8: 7729-7739, 2017. 